\title{
Analisis Materi Volume Benda Putar pada Aplikasi Cara Kerja Piston di Mesin Kendaraan Roda Dua
}

\author{
Pandri Ferdias ${ }^{1}$, Eka Anis Savitri ${ }^{2}$ \\ 1,2IAIN Raden Intan: pferdias@gmail.com \\ Submitted : 15-07-2015, Revised : 16-10-2015, Accepted : 16-12-2015
}

\begin{abstract}
This study only analyzes how the piston works on a two-wheeled engine that is four-step gasoline motor. The first four steps of the gasoline engine is the suction step, the piston moves from the top dead point (TMA) to the bottom dead point (TMB) to suck the fuel (gasoline and air mixture) into the combustion chamber, the second is the compression step The piston moves from the lower dead point (TMB) to the top dead point (TMA) to increase the gasoline and air pressure to obtain a high enough combustion pressure, the third is the working step of the piston moving from the top dead point (TMA) to the bottom dead point (TMB) to continue the combustion pressure force so that it can be used as propulsion, the fourth is the exhaust step of the piston moving from the lower dead point (TMB) to the top dead point (TMA) to remove the combustion gases from the combustion chamber. These four things happen in a working process of a gasoline motor called a cycle. In the gasoline motor, the piston is a tool that performs the four things by moving the piston up and down inside a combustion chamber to generate power. To know the size of cc (centimetercubic) of a vehicle's combustion chamber is by using the rotary volume formula $V=\pi \int_{a}^{b}(f(x))^{2} d x$, the result is $35 \pi$ unit volume, In which there is a certain Integral concept by using the Basic Theorem of Calculus, and by using the function definition, the tube diameter size is contained in the Revo 110 Honda Repair Manual, whereas the height of the tube is measured significantly by using the sliding term. The height of the tube is substituted as the Integral boundary $(a, b)$ and the radius of the tube is substituted as $y=f(x)$. Thus, the greater the volume of a vehicle's engine combustion chamber, the greater the power generated by the piston, the more fuel it needs.
\end{abstract}

Keywords: Basic Theorem of Calculus; Piston; Volume of rotary objects.

\begin{abstract}
Abstrak
Penelitian ini hanya menganalisa cara kerja piston pada mesin kendaraan roda dua yaitu motor bensin empat langkah. Cara kerja motor bensin empat langkah yang pertama adalah langkah hisap yaitu piston bergerak dari titik mati atas (TMA) ke titik mati bawah (TMB) untuk menghisap bahan bakar (campuran bensin dan udara) masuk ke dalam ruang bakar, yang kedua adalah langkah kompresi yaitu piston bergerak dari titik mati bawah (TMB) ke titik mati atas (TMA) untuk menaikkan tekanan bensin dan udara agar diperoleh tekanan pembakaran yang cukup tinggi, yang ketiga adalah langkah kerja yaitu piston bergerak dari titik mati atas (TMA) ke titik mati bawah (TMB) untuk meneruskan gaya tekanan hasil pembakaran sehingga
\end{abstract}


dapat dipakai sebagai tenaga penggerak, yang keempat adalah langkah buang yaitu piston bergerak dari titik mati bawah (TMB) ke titik mati atas (TMA) untuk membuang gas-gas hasil pembakaran keluar ruang pembakaran. Keempat hal tersebut terjadi dalam satu kerja proses motor bensin yang disebut juga satu siklus. Pada motor bensin, piston adalah alat yang melakukan ke- empat hal tersebut dengan cara piston bergerak naik turun didalam sebuah ruang bakar untuk menghasilkan tenaga. Untuk mengetahui besar cc (centimeter cubic) dari sebuah volume ruang bakar kendaraan adalah dengan menggunakan rumus volume benda putar yaitu $V=\pi \int_{a}^{b}(f(x))^{2} d x$, didapatkan hasil yaitu $35 \pi$ satuan volume, yang didalamnya terdapat konsep Integral tertentu dengan menggunakan Teorema Dasar Kalkulus, serta dengan menggunakan definisi fungsi, ukuran diameter tabung terdapat pada Buku Pedoman Reparasi Honda Revo 110, sedangkan tinggi tabung diukur secara nyata dengan mengguanakan jangka sorong. Tinggi tabung disubstitusikan sebagai batas Integral $(a, b)$ dan jari-jari tabung disubstitusikan sebagai $y=f(x)$. Jadi, semakin besar volume dari sebuah ruang bakar mesin kendaraan, maka semakin besar pula tenaga yang dihasilkan oleh piston, sehingga bahan bakar yang diperlukan juga semakin besar.

Kata kunci: Piston; Teorema Dasar Kalkulus; Volume Benda Putar.

\section{PENDAHULUAN}

Pendidikan merupakan faktor terpenting yang perlu ditingkatkan kualitasnya. Selain itu juga pendidikan sangat berperan terhadap maju mundurnya bangsa, karena pendidikan merupakan salah satu upaya mencerdaskan kehidupan bangsa. Semakin luas pengetahuan yang dimiliki seseorang maka akan semakin tinggi pula taraf berfikir. Pendidikan adalah usaha sadar dan terencana untuk mewujudkan suasana belajardan proses pembelajaran agar siswa secara aktif mengembangkan potensi dirinya untuk memiliki kekuatan spiritual keagamaan, pengendalian diri, kepribadian, kecerdasan, akhlak mulia, serta keterampilan yang diperlukan dirinya dan masyarakat.

Dalam kehidupan sehari-hari, kita sering menggunakan kendaraan, baik kendaraan roda dua atau kendaraan roda empat. Selain itu, mungkin tanpa sadar kita juga selalu dekat dengan ilmu geometri. Tahukah dimana letak kedekatan itu? Bagaimana cara kerja dari suatu mesin kendaraan? Serta bagaimana pula melakukan sebuah penghitungan sebuah volume pada komponen mesin kendaraan serta cara pengukuran bagian-bagianyang tepat? Ternyata, salah satu letak kedekatan ini adalah penggunaan geometri untuk merancang mesin kendaraan. Pada mesin mobil maupun motor, besarnya tenaga yang dapat dihasilkan dinyatakan dalam satuan cc (centimeter cubic). Pada dasarnya prinsip kerja mesin maupun mobil bergantung pada kemampuan piston dalam mengonversikan pembakaran campuran antara bahan bakar dan udara yang terjadi di dalam ruang pembakaran. Secara signifikan, semakin besar dimensi ruang pembakaran maka tabung tempat terjadinya pembakaran akan semakin besar. Akibatnya semakin banyak campuran udara dan bahan bakar yang dapat masuk untuk diproses. Akhirnya tenaga yang dapat dihasilkan cukup besar.

Bangun tabung yang ada pada piston merupakan tempat pembakaran yang termasuk salah satu bahasan di dalam geometri dimensi tiga, setelah diketahui volume sebuah tabung dengan geometri dimensi tiga, yang sudah dikaji sebelumnya Moh. Hasan dari UIN Sunan Kalijaga, Yogyakarta yang berjudul "Aplikasi Geometri dalam Membandingkan Kinerja Mesin Berpiston (Torak) Tunggal Empat Langkah dengan Dua Langkah". Kemudian penulis akan 
melakukan kajian yang berbeda, yakni dengan menggunakan rumus volume benda putar dengan menggunakan metode kulit tabung. Pembuktian rumus volume benda putar dengan menggunakan metode kulit tabung yang dilakukan yakni dengan menggunakan konsep integral tentu yang ada pada Teorema Dasar Kalkulus dengan menggunakan ukuran diameter, jari-jari dan kedalaman yang terdapat pada sebuah tabung tersebut. Rumus volume benda putar dengan menggunakan metode kulit tabung ini akan digunakan untuk membuktikan bahwa rumus tersebut dapat digunakan untuk menghitung cc (centimeter cubic) pada sebuah mesin kendaraan.

\section{METODE PENELITIAN}

Penelitian ini merupakan penelitian kualitatif deskriptif. Dalam penelitian ini, deskripsi yang dimaksud adalah mempelajari secara mendalam bagaimana menganalisis materi volume benda putar dan aplikasinya, serta cara kerja piston di mesin kendaraan rodaa dua.

\section{HASIL PENELITIAN DAN PEMBAHASAN}

Analisis Materi Volume Benda Putar pada Aplikasi Cara Kerja Piston di Mesin Kendaraan Roda Dua

Berdasarkan teorema A, Andaikan $f$ kontinu (karenanya a terintegralkan) pada $[a, b]$ dan andaikan $F$ sebarang anti turunan dari $f$ disana. Maka

$$
\int_{a}^{b} f(x) d x=F(b)-F(a)
$$

Bukti Andaikan $P$ : $a=x_{0}<x_{1}<x_{2}<\cdots<x_{n-1}<x_{n}=b$ adalah partisi sebarang dari $[a, b]$. Maka akal "kurangkan-dan-tambahkan" yang baku memberikan:

$$
\begin{aligned}
F(b)-F(a) & =F\left(X_{n}\right)-F\left(X_{n-1}\right)+F\left(X_{n-1}\right)-F\left(X_{n-2}\right)+F\left(X_{n-2}\right)+\cdots+F\left(X_{i}\right)-F\left(X_{0}\right) \\
& =\sum_{i=1}^{n}\left[F\left(X_{i}\right)-F\left(X_{i-1}\right)\right]
\end{aligned}
$$

Menurut Teorema Nilai Rata-rata untuk Turunan, yaitu:

Jika $f$ kontinu pada selang tertutup $[a, b]$ dan terdeferensial pada titik-titik dalam dari $(a, b)$, maka terdapat paling sedikit satu bilangan $c$ dalam $(a, b)$ di mana $\frac{f(b)-f(a)}{b-a}=f^{\prime}(c)$ atau, secara setara, di mana $f(b)-f(a)=f^{\prime}(c)(b-a)$

Menurut Teorema Nilai Rata-rata untuk Turunan yang diterapakan pada $F$ pada selang $\left[X_{i-1}, X_{i}\right]$,

$$
F\left(x_{i}\right)-F\left(x_{i-1}\right)=F^{\prime}\left(\bar{x}_{i}\right)\left(x_{i}-x_{i-1}\right)=f\left(\bar{x}_{i}\right) \Delta x_{i}
$$

Untuk suatu pilihan $\bar{x}_{i}$ dalam selang terbuka $\left(x_{i-1}, x_{i}\right)$. Jadi,

$$
F(b)-F(a)=\sum_{i=1}^{n} f\left(\bar{x}_{i}\right) \Delta x_{i}
$$

Pada ruas kiri kita mempunyai sebuah konstanta; pada ruas kanan kita mempunyai jumlah Riemann untuk $f$ pada $[a, b]$. Bilamana kedua ruas diambil limitnya untuk $|P| \rightarrow 0$, kita peroleh 


$$
F(b)-F(a)=\lim _{|P| \rightarrow 0} \sum_{i=1}^{n} f\left(\bar{x}_{i}\right) \Delta x_{i}=\int_{a}^{b} f(x) d x
$$

Diawali dengan menggunakan rumus volume tabung (geometri dimensi tiga) yaitu $V=\pi r^{2} t$ yang disubstitusikan kedalam rumus volume benda putar yaitu $V=\pi \int_{a}^{b}(f(x))^{2} d x$, dimana $y=f(x)$ adalah jari-jari tabung, sedangkan $\int_{a}^{b} d x$ adalah tinggi tabung, hal ini dikarenakan saat volume benda yang diputar mengelilingi sumbu $X$ sejauh $360^{\circ}$ (secara horizontal) tinggi tabung adalah batas integral $(a, b)$ yaitu $x=a=0$ dan $x=b=5,6$. Tinggi tabung disubstitusikan sebagai batas integral karena tinggi tabung bersifat konstan (tetap) sehingga walaupun batas integral dapat diubah namun selisih dari batas integral tersebut tetap sesuai dengan tinggi dari tabung tersebut. Sehingga didapatkan hasil sebagai berikut:

$$
\begin{aligned}
& V=\pi \int_{a}^{b}\left(f(x)^{2} d x\right. \\
& V=\pi \int_{0}^{5,6}(2,5)^{2} d x \\
& V=\pi \int_{0}^{5,6} 6,25 x d x \\
& V=\pi(6,25(5,6))]_{0}^{5,6} \\
& V=3,14(17,5) \\
& V=109,9 \text { satuan volume } \\
& V=110 \mathrm{~cm}^{3}=110 \mathrm{cc} \text { (centimeter cubic) }
\end{aligned}
$$

Hasil ini juga akan berlaku untuk volume benda yang diputar terhadap sumbu y.

\section{SIMPULAN DAN SARAN}

Berdasarkan hasil penelitian dari tinjauan kepustakaan yang telah dilakukan, maka dapat disimpulkan bahwa adanya keterkaitan dari materi volume benda putar pada aplikasi cara kerja piston di mesin kendaraan. Hal ini dikarenakan karena piston adalah alat untuk membantu pergerakan mesin. Piston terletak didalam ruang bakar yang berbentuk tabung. Volume dari sebuah tabung ini yang menghasilkan besar cc (centimeter cubic) pada sebuah mesin kendaraan. Semakin banyak campuran udara dan bahan bakar yang dapat masuk untuk diproses, maka tenaga yang dapat dihasilkan cukup besar. Jadi semakin besar volume atau cc dari sebuah mesin kendaraan, maka akan semakin besar pula tenaga yang dapat dihasilkan, sehingga bahan bakar yang diperlukan juga semakin besar.

Dalam penelitian yang telah dilakukan, berdasarkan hasil pengukuran dari komponen ruang bakar diantaranya diameter dalam dan kedalaman sebuah ruang bakar piston yang berbentuk tabung, serta dari berbagai sumber referensi yang telah penulis dapatkan. Dari berbagai refrensi tersebut telah dibuktikan bahwa, mencari volume ruang bakar yang berbentuk tabung, dapat menggunakan rumus volume benda putar, yaitu dengan $V=$ $\pi \int_{a}^{b}(f(x))^{2} d x$ (volume benda putar mengelilingi sumbu $X$ sejauh $360^{\circ}$ ) dengan menggunakan rumus volume benda putar yang didalamnya terdapat konsep Integral tertentu dengan menggunakan Teorema Dasar Kalkulus, serta dengan menggunakan definisi fungsi, didapatkan hasil dari sebuah volume sebuah ruang bakar mesin kendaraan roda dua yang ukuran diameternya terdapat pada Buku Pedoman Reparasi Honda Revo 110. Sedangkan 
tinggi tabung didapat dari pengukuran nyata di Balai kerja Otomotif MAN 2 Bandar Lampung. Jari-jari tabung disubstitusikan sebagai $y=f(x)$. dan tinggi atau kedalaman sebuah tabung disubstitusikan sebagai batas integral. Begitu pula dengan $V=\pi \int_{a}^{b}(f(y))^{2} d y$ (volume benda putar mengelilingi sumbu $Y$ sejauh $360^{\circ}$ ). Jari-jari tabung disubstitusikan sebagai $x=f(y)$ dan tinggi atau kedalaman sebuah tabung disubstitusikan sebagai batas integral.

\section{DAFTAR PUSTAKA}

Beni Setya Nugraha, "Aplikasi Teknologi Injeksi Bahan Bakar Elektronik (Efi) Untuk Mengurangi Emisi Gas Buang Sepeda Motor" (Yogyakarta: Fakultas Teknik Universitas Negeri Yogyakarta, 2007)

Booth, J. Dexter, Matematika Teknik Edisi Kelima Jilid 1

Buku Pedoman Reparasi Honda Revo ( PT. Astra Honda Motor, 8-3)

Cholik, M. Adinawan, Sugijono, Matematika Kelas VIII , Erlangga, Jakarta, 2008

Damai Lisdiana, Isometri Terhadap Geometri Insidensi Terurut . (Skripsi Program S1 Jurusan Matematika F.MIPA UNILA, Bandar Lampung, 2013), h. 23-25

Designing For Domestication Of Yamaha Cy80 Engine Piston Manufacturing Technology And Evaluation Of Aluminum Alloy (4032-T6) For Functionality (International journal of advanced scientific and technical research Issue 5 volume 1, January-February 2015) tersedia di : Available online on http://www.rspublication.com/ijst/index.html ISSN 2249-9954

Edwin J. Purcell, Dale Varberg, Kalkulus Dan Geometri Analitis Jilid 1 Edisi Kelima (Jakarta: Erlangga)

Indarti, Peranan Pemerintah Indonesia dalam Gerakan Non Blok pada tahun 1956. (Skripsi Program S1 Jurusan Pendidikan Sejarah FKIP UNILA, Bandar Lampung, 2010), h. 16-19

International Journal of Innovative Research in Engineering \& Scienc ISSN 2319-5665 (January 2013, issue 2 volume 1)

Investigation of Two Engine Pistons by FEA (International Journal of Research (IJR) Vol-1, Issue11 December 2014 ISSN 2348-6848)

Jalius Jama, Wagino, Teknik Sepeda Motor Jilid II Untuk SMK, Direktorat Sekolah Menengah Kejuruan, Jakarta, 2008

John Bird, Matematika Dasar Teori dan Aplikasi Praktis Edisi Ketiga (Jakarta: Erlangga, 2006) K.A Stroud, Matematika Teknik Edisi Kelima Jilid 2

Kamta Agus Sajaka, et. al. Matematika Interaktif Jilid 3A Program IPA: Yudhistira, Bogor, 2007 Kasmina, dkk, Matematika Program Keahlian Teknologi, Kesehatan, dan Pertanian untuk SMK dan MAK Kelas XI, Erlangga, Jakarta, 2008.

M. Suratman, Servis dan Reparasi Auto Mobil (Bandung: Pustaka Grafika, 2001)

Moh. Hasan, "Aplikasi Geometri dalam Membandingkan Kinerja Mesin Berpiston (Torak)

Tunggal Empat Langkah dengan Dua Langkah" (Yogyakarta:UIN Sunan Kalijaga, 2013)

Mushaf Sahmalnour, Sahm Al Nour Trust, Jakarta, 2007)

"Pendidikan Teknik Otomotif" (On-line) tersedia di: http://unnes.ac.id/prodi/pendidikanteknik-otomotif/

Suah Sembiring, Penuntun Pelajaran Matematika Berdasarkan Kurikulum 1984 Untuk SMA

(Bandung: Ganeca Exact Bandung, 1986)

Suharto, Matematika Terapan Untuk Perguruan Tinggi, Rineka Cipta, Malang, 1991 
Sukino, Simangunsong Wilson, Matematika untuk SMP Kelas IX, Erlangga, Jakarta 2006 Sumadi, dkk, Matematika Kelas IX untuk SMK MAK, Saka Mitra Kompetensi, Klaten, 2006 Sumargo, Daftar Dan Sari Matematika, Angkasa Bandung, Salatiga, 1985

Susanto, et. al. Motor Bensin (Jakarta: Cv. Fariska Utama, 2000)

Tim Fisika Dasar, Penuntun Praktikum Fisika Dasar I, Tim Fisika Dasar IAIN Raden Intan Lampung, Bandar Lampung, 2011

Tim Penyusun, PR Fisika Kelas 1 SMU Tengah Tahun Pertama, PT Intan Pariwara, Klaten, 2002 Wiraatmaja, "Cara Kerja Motor Bensin 4 Langkah (On-line) diposting oleh Sahil Luqman (Jurnal Ilmiah Teknik Mesin Vol. 4 No.1. April 2010) 